\section{How many 24-hour recalls or food records are required to estimate usual energy and nutrient intake?}

\author{
Quantos recordatórios de 24-horas ou registros \\ alimentares são necessários para estimar 0 \\ consumo usual de energia e nutrientes?
}

\author{
${ }^{1}$ Instituto de Nutrição Josué \\ de Castro, Universidade \\ Federal do Rio de Janeiro, \\ Rio de Janeiro, Brasil. \\ 2 Instituto de Saúde da \\ Comunidade, Universidade \\ Federal Fluminense, \\ Niterói, Brasil. \\ Correspondence \\ R. A. Pereira \\ Deptartamento de Nutrição \\ Social Aplicada, Instituto \\ de Nutrição Josué de Castro, \\ Universidade Federal do Rio \\ de Janeiro. \\ Av. Carlos Chagas Filho 373 , \\ Edifício do Centro de \\ Ciências, Rio de Janeiro, $R J$ \\ 21941-590, Brasil. \\ roapereira@ufrj.br
}

\begin{abstract}
For dietary intake assessments, one needs to know the minimum 24-hour recall or food record replications that are required to estimate usual energy and nutrient intake and to classify subjects correctly according to their nutrient intake. Data from two different studies on dietary intake that were carried out with 300 adults and 169 adolescents in the Rio de Janeiro Metropolitan area, Brazil, were analyzed. To estimate the number of replications two methods were applied: one based on the variances ratio, the other based on the within-subject variance alone. The most important results found were the requirement for 14 replications for boys and men, 15 for girls, and 23 for women in order to estimate energy intake with a precision of $90 \%$. Also four replications for boys and seven for men, girls and women are required to classify individuals' energy intake with a correlation coefficient of 0.9. Due to the within variance in food intake, a larger number of replications is required to obtain estimates of usual intakes than is needed to classify subjects according to levels of dietary intake.
\end{abstract}

Food Consumption; Diet Surveys; Adult; Adolescent
Rosângela Alves Pereira 1 Marina Campos Araujo 1 Taís de Souza Lopes 1 Edna Massae Yokoo ${ }^{2}$

\section{Introduction}

The relevance of food intake in nutrition and health studies is already acknowledged. However, the measurement of food intake needs methods that combine simplicity, validity, and accuracy, which is a challenge given the constraints involved in this task 1,2 .

Food records, 24-hour dietary recall (24hR), and the food frequency questionnaire (FFQ) are the most common dietary assessment methods. Food records and $24 \mathrm{hR}$ recalls are based on foods and amounts actually consumed by an individual on one or more specific day. FFQ obtain retrospective information on the intake of specific foods during a longer period ${ }^{3}$, allowing to estimate usual diet, which can be described as the mean intake over an extended period of time $3,4,5$.

Recall and record methods are often applied as reference methods in the assessment of FFQ validity. In this case, the energy and nutrient intake obtained by the FFQ is compared to the estimates resulting from one or more recalls or records from a representative sub sample in the study population 3 .

Instruments for dietary assessment should take into account the wide variability observed in individuals' and groups' intake. Food intake is affected by daily, weekly, and seasonal variations, and tends to suffer profound changes over the years. Therefore, to estimate associations between diet and health it is necessary to estimate 
an individual's usual intake 1,3. Variability in food intake arises because each individual differs in the types and amounts of food consumed from one day to the next (intra-individual or withinsubject variability) and also because individuals differ from each other in their food intakes (interindividual or between-subject variability) 3,6.

The error caused by the variation above and below an individual's true long-term intake is the main source of random error in dietary data obtained for one or several days; this error tends to vary according to the dietary factor under observation: energy, nutrients or foods. For methods that are based on the assessment of one day of dietary intake, if one or several days are taken into account to estimate usual food intake, beyond errors in the individuals' estimates, random errors are also observed when comparing individuals. Such errors can lead to biased estimates of the association between dietary factors and an outcome and can modify FFQ validity estimators $2,6,7,8$.

Therefore one or two days of food intake reporting does not usually represent with accuracy the usual food intake, and any estimations derived from such records may be spurious. It has been demonstrated that the within-subject variance can be used to estimate the number of $24 \mathrm{hR}$ or food records required to estimate usual intake of energy, nutrients, and food groups 9,10.

For the Rio de Janeiro population, there are no studies estimating the number of replications required for assessing energy and nutrient intake for adults and adolescents. Nonetheless, this information is crucial for epidemiological studies analyzing the relationship between diet and disease, since it is necessary to correctly classify an individual's dietary intake and/or to estimate with good precision the usual absolute energy and nutrient intake, in order to avoid spurious estimators.

In this article, data from two different studies on dietary intake carried out among adolescents and adults from the Rio de Janeiro Metropolitan Area were analyzed with the objective of determining the number of $24 \mathrm{hR}$ and food records replications required to estimate usual energy and nutrients intake. Two methods were applied; the first is based on the within/between-subjects variances ratio for energy and nutrient intake 7,11. And the second is based on the within-subject variance alone 7,12 . We also estimated the nutrient intake crude means and de-attenuated in order to help understand the variability behavior across the different items analyzed.

\section{Methods}

\section{Adolescents}

The study with adolescents was approved by the Institutional Review Board of the University of the State of Rio de Janeiro on January 13, 2005; study participants over the age of 18 or the legal guardians of younger adolescents signed informed consent forms. The data were collected between May, 2005 and November, 2006. The purpose of the study was to validate a FFQ designed for adolescents living in the Rio de Janeiro Metropolitan area having as reference method a set of three food records. The selection of participants was planned to include individuals aged between 12 and 19 drawn from different socioeconomic backgrounds and areas. Therefore, a non-probability convenience sample of 169 adolescents (100 girls and 69 boys) from sixth and seventh grades of a public school in Niterói ( $\mathrm{n}=$ 66), from high school in a private school of Rio de Janeiro $(n=38)$, and from a low-income neighborhood in Duque de Caxias $(n=65)$ completed three food records on non-consecutive days.

The adolescents wrote down every food and beverage (except water) that they have consumed on two weekdays and on one weekend day during a three week period. Their notes also included preparation, ingredients, measurements based on household utensils or volume and mass units, and the time and place of meals. To improve the quality of the recorded information, on the following day of the register, the records were reviewed by a nutritionist along with the adolescents.

\section{Adults}

The study sample included 263 adults (123 men and 140 women), 20-59 years old, sub sampled from a population-based survey conducted in Duque de Caxias, a municipality in the Rio de Janeiro Metropolitan area. This study was approved by the Institutional Review Board of the Institute of Collective Health, Federal University of Rio de Janeiro; participants signed informed consent forms. The participants completed three 24hR obtained on non-consecutive days during a one-month period. The data were collected in face-to-face interviews administered by trained nutritionists from March to December, 2007.

\section{Body mass index (BMI)}

Adolescents were weighed using an electronic portable scale to the nearest $0.1 \mathrm{~kg}$ (Plenna, São Paulo, Brazil) and height was measured with a 
portable stadiometer (Alturaexata, Belo Horizonte, Brazil). Adults also were weighed with an electronic portable scale to the nearest $0.1 \mathrm{~kg}$ (Tanita mod. BC553, Arlington Heights, USA) and the stature was measured with a portable stadiometer (Sanny, São Bernardo do Campo, Brazil). BMI was estimated as weight (in $\mathrm{kg}$ ) $/ \mathrm{height}^{2}$ (in $\mathrm{m})$. The nutritional status was classified according to the World Health Organization (WHO) 13 proposal for adults. For adolescents, the age-sex specific BMI cutoffs proposed by the International Obesity Task Force (IOTF) 14 were used to diagnose overweight and obesity. To identify low weight among adolescents the criteria proposed by the WHO were applied 13 .

\section{Data analysis}

The software Nutwin (Escola Paulista de Medicina, Universidade Federal de São Paulo, São Paulo, Brazil), which is based on the United States Department of Agriculture (USDA) database, was used to estimate the daily intake of energy, carbohydrates, protein, lipids, fiber, cholesterol, calcium, iron, and vitamins A and C. For items that were not included in the Nutwin software food composition table, the centesimal composition was obtained from the Brazilian Food Composition Table (TACO, version 1. Núcleo de Estudos e Pesquisas em Alimentação, Universidade Estadual de Campinas, Campinas, Brazil). Standard recipes 15 and serving sizes 16 were used to estimate the nutritional composition of preparations that were not included in the software database.

The within- and between-subject variances were calculated for the food records and $24 \mathrm{hR}$ estimations of energy and nutrients intake. Crude and de-attenuated mean intakes were estimated for both adolescents and male and female adults, based on the three food records and $24 \mathrm{hR}$ means. The intake of energy and nutrients was de-attenuated using the methodology proposed by the Iowa State University 17,18 and PC-Side v.1.0 (Software for Intake Distribution Estimation. The Center for Agricultural and Rural Development, Iowa State University, Iowa, USA).

The Iowa State University method is based on a complex model that uses a two-stage transformation to obtain estimates of usual energy and nutrient intakes from food records and $24 \mathrm{hR}$. The advantage of using this method over the traditional analysis using regression models or ANOVA is the possibility of allowing the within-person variance to vary across individuals, reflecting the fact that some individuals may have a more varied diet than others and it can also account for biases due to seasonality, day-of-week, and time-in-sample effects as part of its initial adjustments 19,20.

To apply the Iowa State University method the PC-Side software was used which is designed to examine the distribution of each nutrient and perform the appropriately transform skewed distributions using the Box-Cox procedures and also to perform adjusted back-transformation of the data 19. The PC-Side uses a measurement error model for observed daily intakes, in which the observed intake for an individual on any day is equal to that individual's usual intake plus a measurement error. The usual intake variance is the inter-individual variance (between individuals variance: $\sigma_{b}^{2}$ ), while the measurement errors variance is the intra-individual variance (within individual variance: $\sigma_{\omega}^{2}$ ) 17 . To correct the values of individual intake obtained by the $24 \mathrm{hR}$ applying the measurement error model as described by Dodd et al. 19, it is necessary to estimate the de-attenuation factor $(\omega)$ which is done by:

$$
\omega=\sqrt{\frac{\sigma_{b}^{2}}{\sigma_{b}^{2}+\frac{\sigma_{\omega}^{2}}{n}}} \text { (equation 1) }
$$

Where, $\sigma_{b}^{2}$ : between individuals variance; $\sigma_{\omega}^{2}$ : within individual variance; $n$ : number of individuals.

The de-attenuation factor is multiplied by the estimated individual means (of two $24 \mathrm{hR}$ ) to estimate the intermediaries' values, which did not represent the real individuals' intakes but are used to describe the distribution of de-attenuated typical intakes 19 .

Replications of $24 \mathrm{hR}$ and food records in the estimation of the usual intake

The number of $24 \mathrm{hR}$ or food records required to obtain reliable estimates of nutrient intake was determined by two different methods: one using both within- and between-subject variances and another using only the within-subject variability.

Black et al. 11 proposed a method to estimate the number of replications of food records and $24 \mathrm{hR}$ based on the expected correlation coefficient between the observed and actual intakes (equation 2). A higher value of $r$ indicates a higher proportion of subjects correctly classified and a lower proportion of misclassified individuals. If the within/between variances ratio is low, then fewer days of observation are required to classify subjects correctly.

$$
\mathrm{d}=\frac{\mathrm{r}^{2}}{1-\mathrm{r}^{2}} \frac{\mathrm{s}_{\mathrm{w}}^{2}}{\mathrm{~s}_{\mathrm{b}}^{2}} \text { (equation 2) }
$$


Where, $\mathrm{d}$ : is the number of replications required; $\mathrm{r}$ : is the expected correlation coefficient between observed and true intakes (in this study, estimations were calculated for $\mathrm{r}=0.7,0.8$ and 0.9$) ; \frac{\mathrm{s}_{\mathrm{w}}^{2}}{2}$ : is the within- between-subject variance ratio. $\mathrm{s}_{\mathrm{b}}^{2}$

On the other hand, Beaton et al. 12 estimated the number of replications of $24 \mathrm{hR}$ and food records taking into account the estimation of intakes of energy and nutrients with a given level of confidence (equation 3). Using this calculation, the number of days calculated allows the observed mean intake to lie within a specified percentage of the true mean in $95 \%$ of the estimations.

$$
\mathrm{d}=\left(\mathrm{Z}_{\alpha}, \mathrm{CV}_{\mathrm{w}} \mathrm{D}\right)^{2} \text { (equation 3) }
$$

Where: $\mathrm{d}$ : is the number of replications required; $\mathrm{Z}_{\alpha}$ : is the normal deviate, e.g., 1.96; $\mathrm{CV}_{\mathrm{w}}$ : is the within-subject coefficient of variation, calculated as square root of within-subject variance (standard deviation) divided by the mean intake; D: is the specified error given as a percentage of the true usual intake. In this study, estimates of replications were done considering $10 \%$ and $20 \%$ of error.

\section{Results}

\section{Adolescents}

The adolescents' mean age was 15.4, standard deviation (SD) was 1.9 years old, plus $44 \%(n=74)$ of the adolescents were under the age of 15 years. There were no statistically significant differences in age distribution for boys and girls. The prevalence of overweight was 15\% (Table 1).

For girls, the de-attenuated means of nutrient intake tended to be slightly higher than crude means, except for protein, that suffered a reduction, and polyunsaturated fat, that did not change after de-attenuation. For boys, the means reduced after de-attenuation, except for carbohydrate, fiber, and vitamin A. As was expected, the distributions' standard deviation reduced after de-attenuation for both genders (Table 2).

Within- and between-subject variance ratios ranged from 0.9 (calcium) to 3.0 (vitamin A) for boys and from 1.3 (calcium) to 9.0 (polyunsaturated fat) for girls, demonstrating that girls presented higher within-subject variability than boys (Table 3 ).

For boys, the number of required replications of $24 \mathrm{hR}$ and food records based on expected correlation coefficients between observed and real intake equal to 0.8 ranged from two (energy, carbohydrate, total fat, saturated fat, calcium, iron) to five days (cholesterol); and for girls, those figures ranged from two (calcium) to 16 days (poly- unsaturated fat) (Table 4). The estimation of the required replications of $24 \mathrm{hR}$ and food records based on the admitted error and on the withinsubject coefficient of variation resulted in a larger number of replications. The estimations of usual energy and nutrient intakes within $10 \%$ of error would require from 14 (energy) to 311 days (vitamin A) for boys and from 11 (protein) to 172 days (vitamin A) for girls (Table 5). As expected, the estimations with $20 \%$ error needed fewer replications: the maximum number of replications required for boys was 78 days and for girls, 43 days (Table 4).

\section{Adults}

The mean age of adults was $41.4, \mathrm{SD}=11.2$ years old, and $43 \%$ of the examined sample $(n=112)$ were aged between 20 and 40 . There were no statistically significant differences in the distribution of age for men and women. The prevalence of overweight was $66 \%$ (Table 1 ).

For women, the de-attenuated means of energy, cholesterol and vitamin A were slightly higher than crude means and the mean intake of calcium reduced after de-attenuation. The other nutrient did not modify or suffered minor changes after de-attenuation. For men, the means of energy, protein, carbohydrate, total fat, calcium, and vitamin A reduced after de-attenuation; for the other nutrient the means did not change. As was the case with the adolescents, the standard deviations reduced after de-attenuation (Table 5).

Within- and between-subject variances ratios ranged from 1.0 (carbohydrate) to 15.6 (cholesterol) for men and from 1.7 (energy) to 4.3 (vita$\min$ A) for women (Table 3 ).

The estimation of the required replications of $24 \mathrm{hR}$ and food records to estimate usual energy and nutrient intakes based on correlation coefficients equal to 0.8 ranged from two (energy) to 28 days (cholesterol) for men and three (energy, carbohydrate, total fat) to eight days (vitamin A) for women (Table 4).

The estimation of the required replications of $24 \mathrm{hR}$ and food records based on $10 \%$ error in the estimation of absolute energy and nutrient intake resulted in more replications, mainly for calcium (37 replications) and fiber (30 replications) for men and fiber (46 replications) and cholesterol (50 replications) for women (Table 5). As expected, to estimate nutrient intakes within $20 \%$ of usual intake, less repetitions were required, reaching the maximum of nine days (calcium) for men and 12 replications (cholesterol, fiber) for women (Table 4). 
Table 1

Distribution of adults and adolescents according to gender, age range and weight status. Rio de Janeiro Metropolitan Area, Brazil, 2005-2007.

\begin{tabular}{|c|c|c|c|c|}
\hline & \multicolumn{2}{|c|}{ Adolescents $(\mathrm{N}=169)$} & \multicolumn{2}{|c|}{ Adults $(N=263)$} \\
\hline & $\mathrm{n}$ & $\%$ & $\mathrm{n}$ & $\%$ \\
\hline \multicolumn{5}{|l|}{ Gender } \\
\hline Male & 69 & 41 & 123 & 47 \\
\hline Female & 100 & 59 & 140 & 53 \\
\hline \multicolumn{5}{|l|}{ Age (years) } \\
\hline $12-15$ & 74 & 44 & - & - \\
\hline $15-18$ & 95 & 56 & - & - \\
\hline $20-40$ & - & - & 112 & 43 \\
\hline $40-60$ & - & - & 151 & 57 \\
\hline \multicolumn{5}{|l|}{ Weight status * } \\
\hline Low weight & 10 & 6 & 2 & 1 \\
\hline Normal weight & 127 & 75 & 83 & 32 \\
\hline Overweight & 25 & 15 & 169 & 64 \\
\hline
\end{tabular}

* There was no information on anthropometric measurements for seven adolescents and nine adults.

Table 2

Energy and nutrient crude and de-attenuated mean intake (standard deviation - SD) and 95\% confidence interval (95\% Cl) of adolescents. Rio de Janeiro Metropolitan Area, Brazil, 2005-2007.

\begin{tabular}{|c|c|c|c|c|c|c|}
\hline \multirow[t]{2}{*}{ Energy/Nutrients } & \multicolumn{3}{|c|}{ Crude } & \multicolumn{3}{|c|}{ De-attenuated } \\
\hline & Mean & $95 \% \mathrm{Cl}$ & SD & Mean & $95 \% \mathrm{Cl}$ & SD \\
\hline \multicolumn{7}{|l|}{ Boys $(n=69)$} \\
\hline Energy (kcal) & 2,456 & $2,258-2,653$ & 821 & 2,430 & $2,274-2,586$ & 649 \\
\hline Protein (g) & 87 & $80-94$ & 29 & 86 & $81-91$ & 21 \\
\hline Carbohydrate (g) & 343 & $316-371$ & 115 & 349 & $326-372$ & 97 \\
\hline Total fat (g) & 78 & $70-86$ & 34 & 74 & $68-80$ & 26 \\
\hline Saturated fat (g) & 23 & $20-26$ & 12 & 21 & $19-23$ & 9 \\
\hline Polyunsaturated fat (g) & 11 & $10-12$ & 5 & 11 & $10-12$ & 3 \\
\hline Cholesterol (mg) & 251 & $218-283$ & 136 & 223 & $202-244$ & 88 \\
\hline Fiber (g) & 14 & $12-15$ & 5 & 15 & $14-16$ & 4 \\
\hline Calcium (mg) & 634 & $548-719$ & 357 & 586 & $515-657$ & 294 \\
\hline Iron (mg) & 13 & $11-14$ & 5 & 12 & $11-13$ & 3 \\
\hline Vitamin A (retinol equivalent) & 759 & $576-942$ & 763 & 868 & 698-1039 & 710 \\
\hline \multicolumn{7}{|l|}{ Girls $(n=100)$} \\
\hline Energy (kcal) & 1,980 & $1,851-2,108$ & 648 & 2,019 & $1,917-2,122$ & 518 \\
\hline Protein (g) & 74 & $69-78$ & 23 & 72 & $69-75$ & 14 \\
\hline Carbohydrate (g) & 278 & $259-297$ & 98 & 285 & $270-301$ & 76 \\
\hline Total fat (g) & 64 & $58-69$ & 28 & 67 & $62-71$ & 21 \\
\hline Saturated fat (g) & 20 & $18-23$ & 12 & 22 & $20-24$ & 10 \\
\hline Polyunsaturated fat (g) & 9 & $8-9$ & 3 & 9 & $9-10$ & 2 \\
\hline Cholesterol (mg) & 200 & $181-219$ & 95 & 214 & $203-225$ & 57 \\
\hline Fiber (g) & 11 & $9-12$ & 6 & 12 & $11-13$ & 5 \\
\hline Calcium (mg) & 567 & $502-631$ & 325 & 602 & $552-652$ & 255 \\
\hline Iron (mg) & 10 & $9-11$ & 4 & 11 & $10-11$ & 3 \\
\hline Vitamin A (retinol equivalent) & 604 & $489-718$ & 577 & 703 & $619-786$ & 421 \\
\hline
\end{tabular}


Within and between proportional variance, respective coefficients of variation *, and variance ratio (within/between) for energy and nutrient intake of adults and adolescents **. Rio de Janeiro Metropolitan Area, Brazil, 2005-2007.

\begin{tabular}{|c|c|c|c|c|c|c|}
\hline Energy/Nutrients & $\begin{array}{c}\text { Within } \\
\text { variance } \\
\% \text { (coefficient } \\
\text { of variation) }\end{array}$ & $\begin{array}{c}\text { Between } \\
\text { variance } \\
\% \text { (coefficient } \\
\text { of variation) }\end{array}$ & $\begin{array}{c}\text { Variance } \\
\text { ratio }\end{array}$ & $\begin{array}{c}\text { Within } \\
\text { variance } \\
\% \text { (coefficient } \\
\text { of variation) }\end{array}$ & $\begin{array}{c}\text { Between } \\
\text { variance } \\
\% \text { (coefficient } \\
\text { of variation) }\end{array}$ & $\begin{array}{c}\text { Variance } \\
\text { ratio }\end{array}$ \\
\hline Adolescents & & Boys $(n=69)$ & & & Girls $(n=100)$ & \\
\hline Energy (kcal) & 49 (19) & 51 (19) & 1.0 & $62(20)$ & $39(16)$ & 1.6 \\
\hline Protein (g) & $67(21)$ & $34(15)$ & 2.0 & $75(17)$ & $25(10)$ & 3.0 \\
\hline Carbohydrate (g) & $48(20)$ & $52(21)$ & 0.9 & $64(22)$ & $36(16)$ & 1.8 \\
\hline Total fat (g) & $51(24)$ & $5(24)$ & 1.0 & $71(25)$ & $30(16)$ & 2.4 \\
\hline Saturated fat (g) & $55(30)$ & $45(27)$ & 1.2 & $70(36)$ & $31(24)$ & 2.3 \\
\hline Polyunsaturated fat (g) & $70(25)$ & $31(17)$ & 2.3 & $90(18)$ & $10(6)$ & 9.0 \\
\hline Cholesterol (mg) & $74(31)$ & $26(18)$ & 2.9 & $85(26)$ & $15(11)$ & 5.7 \\
\hline Fiber (g) & $69(23)$ & $31(16)$ & 2.2 & $71(34)$ & $29(21)$ & 2.5 \\
\hline Calcium (mg) & $46(34)$ & $54(36)$ & 0.9 & $56(32)$ & 44 (19) & 1.3 \\
\hline Iron (mg) & $58(20)$ & $42(17)$ & 1.4 & $75(23)$ & $26(14)$ & 2.9 \\
\hline Vitamin A (retinol equivalent) & $76(90)$ & $25(52)$ & 3.0 & $72(67)$ & $28(42)$ & 2.6 \\
\hline Adults & & Males $(n=123)$ & & & emales $(n=140)$ & \\
\hline Energy (kcal) & $62(19)$ & $38(15)$ & 1.6 & $63(25)$ & $37(19)$ & 1.7 \\
\hline Protein (g) & $82(19)$ & $18(9)$ & 4.4 & $68(28)$ & $32(19)$ & 2.1 \\
\hline Carbohydrate (g) & $50(21)$ & $50(21)$ & 1.0 & $66(23)$ & $34(17)$ & 1.9 \\
\hline Total fat (g) & $81(20)$ & $19(10)$ & 4.3 & $67(31)$ & $33(22)$ & 2.0 \\
\hline Saturated fat (g) & $85(20)$ & $15(8)$ & 5.6 & $74(29)$ & $26(18)$ & 2.8 \\
\hline Polyunsaturated fat (g) & $78(25)$ & $22(13)$ & 3.4 & $74(28)$ & $26(17)$ & 2.8 \\
\hline Cholesterol (mg) & 94 (19) & $6(5)$ & 15.6 & $80(36)$ & $20(18)$ & 4.0 \\
\hline Fiber (g) & $63(28)$ & $37(22)$ & 1.7 & $69(35)$ & $31(24)$ & 2.2 \\
\hline Calcium (mg) & $69(31)$ & $31(21)$ & 2.2 & $68(31)$ & $32(22)$ & 2.1 \\
\hline Iron (mg) & $84(20)$ & $17(9)$ & 5.0 & $67(30)$ & $33(21)$ & 2.0 \\
\hline Vitamin A (retinol equivalent) & $84(17)$ & $17(8)$ & 4.8 & $82(15)$ & $18(7)$ & 4.3 \\
\hline
\end{tabular}

* Estimated by the square ratio of the intra or inter individual variance divided by the mean energy or nutrient intake

** Intra and inter individual variances estimated applying the software PC-Side v.1.0 (Software for Intake Distribution Estimation. The Center for Agricultural and Rural Development, lowa State University, Ames, USA).

\section{Discussion}

Adjusting energy and nutrient intake estimates by the within and between variance is a crucial step in the analysis of data on food intake in order to reduce errors in dietary intake assessment. Such errors usually introduce bias and/or attenuate association and risk measurements in analytical studies and in validation studies of dietary assessment methods.

The number of $24 \mathrm{hR}$ and food records replications depends on the study objectives, on the dietary factor under observation, on the desirable precision and/or on the expected degree of correlation between the observed and the actual intake ${ }^{3,21}$.

In this study, two methods were applied to estimate the number of $24 \mathrm{hR}$ or food records rep- lications needed to estimate usual food intake. The first is based on the within/between individual variances ratio plus the expected correlation coefficient between observed and actual food intake. The second is based on the intra-individual variation coefficient and in the error tolerated in estimation of absolute values of energy and usual nutrient intake 7 . These two alternatives complement each other as the first is related to the food intake categorization and the second is related to the actual intake estimates. In studies that assess the validity of FFQ against $24 \mathrm{hR}$ or food records, it is recommended to use the number of replications obtained with the method based on the variances ratio and the correlation coefficient. On the other hand, when the study objective is to estimate the absolute usual intake, the method of choice for calculating the number of 
Number of days required for the estimation of energy and nutrients intake according to two different calculations. Rio de Janeiro Metropolitan area, Brazil, 2005-2007.

\begin{tabular}{|c|c|c|c|c|c|c|c|c|c|c|}
\hline \multirow[t]{2}{*}{ Energy/Nutrients } & \multicolumn{3}{|c|}{$\begin{array}{c}\text { Expected correlation } \\
\text { coefficient * }\end{array}$} & \multicolumn{2}{|c|}{ Admitted error $* \star$} & \multicolumn{3}{|c|}{$\begin{array}{c}\text { Expected correlation } \\
\text { coefficient * }\end{array}$} & \multicolumn{2}{|c|}{ Admitted error ** } \\
\hline & 0.9 & 0.8 & 0.7 & $10 \%$ & $20 \%$ & 0.9 & 0.8 & 0.7 & $10 \%$ & $20 \%$ \\
\hline Adolescents & \multicolumn{5}{|c|}{ Boys } & \multicolumn{5}{|c|}{ Girls } \\
\hline Energy (kcal) & 4 & 2 & 1 & 14 & 3 & 7 & 3 & 2 & 15 & 4 \\
\hline Protein (g) & 8 & 4 & 2 & 16 & 4 & 13 & 5 & 3 & 11 & 3 \\
\hline Carbohydrate (g) & 4 & 2 & 1 & 15 & 4 & 8 & 3 & 2 & 18 & 4 \\
\hline Total fat (g) & 4 & 2 & 1 & 22 & 6 & 10 & 4 & 2 & 25 & 6 \\
\hline Saturated fat (g) & 5 & 2 & 1 & 34 & 8 & 10 & 4 & 2 & 51 & 13 \\
\hline Polyunsaturated fat (g) & 10 & 4 & 2 & 24 & 6 & 38 & 16 & 9 & 13 & 3 \\
\hline Cholesterol (mg) & 12 & 5 & 3 & 36 & 9 & 24 & 10 & 5 & 27 & 7 \\
\hline Fiber (g) & 9 & 4 & 2 & 20 & 5 & 10 & 4 & 2 & 43 & 11 \\
\hline Calcium (mg) & 4 & 2 & 1 & 43 & 11 & 5 & 2 & 1 & 40 & 10 \\
\hline Iron (mg) & 6 & 2 & 1 & 15 & 4 & 12 & 5 & 3 & 21 & 5 \\
\hline Vitamin A (retinol equivalente) & 13 & 5 & 3 & 311 & 78 & 11 & 5 & 2 & 172 & 43 \\
\hline Adults & \multicolumn{5}{|c|}{ Males } & \multicolumn{5}{|c|}{ Females } \\
\hline Energy (kcal) & 7 & 3 & 2 & 14 & 4 & 7 & 3 & 2 & 23 & 6 \\
\hline Protein (g) & 18 & 8 & 4 & 13 & 3 & 9 & 4 & 2 & 30 & 7 \\
\hline Carbohydrate (g) & 4 & 2 & 1 & 17 & 4 & 8 & 3 & 2 & 20 & 5 \\
\hline Total fat (g) & 18 & 7 & 4 & 15 & 4 & 8 & 3 & 2 & 36 & 9 \\
\hline Saturated fat (g) & 23 & 10 & 5 & 15 & 4 & 12 & 5 & 3 & 33 & 8 \\
\hline Polyunsaturated fat (g) & 14 & 6 & 3 & 23 & 6 & 11 & 5 & 3 & 30 & 8 \\
\hline Cholesterol (mg) & 67 & 28 & 15 & 14 & 4 & 17 & 7 & 4 & 50 & 12 \\
\hline Fiber (g) & 7 & 3 & 2 & 30 & 8 & 9 & 4 & 2 & 46 & 12 \\
\hline Calcium (mg) & 9 & 4 & 2 & 37 & 9 & 9 & 4 & 2 & 37 & 9 \\
\hline Iron (mg) & 19 & 8 & 4 & 15 & 4 & 8 & 4 & 2 & 34 & 8 \\
\hline Vitamin A (retinol equivalente) & 21 & 9 & 5 & 10 & 3 & 19 & 8 & 4 & 9 & 2 \\
\hline
\end{tabular}

* Equation 1: $d=(r 2 / 1-r)\left(S_{w}^{2} / S_{b}^{2}\right)$, where; $d$ : is the number of replications required; $r$ is the expected correlation coefficiente between observed and true intakes;

$\mathrm{S}_{\mathrm{w}}^{2}$ : is the within; $\mathrm{S}_{\mathrm{b}}^{2}$ : is the between-subject variance 11;

** Equation 2: $d$ : $\left(Z \alpha \cdot C V_{w} . D\right)^{2}$, where; $d$ : is the number of replications required; $Z \alpha$ : is the normal deviate; $C V_{w}$ : is the within-subject coefficient of variation;

D: is the specific error admitted as a percentage of the true usual intake 12

$24 \mathrm{hR}$ and food records replications should be the one based on the intra-individual variance and a certain degree of precision 7,21 .

The study showed that to rank the adolescents' energy intake considering a correlation coefficient of 0.9 , at least four replications of $24 \mathrm{hR}$ or food records would be necessary for boys and seven replications for girls. Costa et al. 4 estimated the variances ratio ranging between 1.35 and 2.62 , and also calculated that at least six replications of $24 \mathrm{hR}$ are needed in order to estimate the usual diet of adolescents from São Paulo, Brazil.

Nelson et al. 21 indicated that at least nine food records replications were needed to obtain a coefficient correlation of 0.9 , in the comparison between observed and actual usual food intake; in this case, the energy intake variances ratios were 1.9 and 2.2 for boys and girls with ages between 5 and 17 years old, respectively.

To observe a correlation coefficient of 0.7 , which can be seen as realistic in studies validating food frequency questionnaires 3 , one day of $24 \mathrm{hR}$ or food records would be enough to estimate energy intake for boys and two replications would be enough for girls. The variance ratios for the macro and micronutrient intake were higher than for energy. Costa et al. 4 also referred to the need for at least 10 dietary assessment repetitions to estimate the usual intake of fat among adolescents from São Paulo. Therefore, studies that seek to calculate associations' measurements between the intake of specific dietary components, like the subtypes of fat, and the risk of developing diseases should be aware of 
Energy and nutrients crude and de-attenuated mean intake (standard deviation - SD) and 95\% confidence interval (95\%Cl) of adults. Rio de Janeiro Metropolitan Area, Brazil, 2007.

\begin{tabular}{|c|c|c|c|c|c|c|}
\hline \multirow[t]{2}{*}{ Energy/Nutrients } & \multicolumn{3}{|c|}{ Crude } & \multicolumn{3}{|c|}{ De-attenuated } \\
\hline & Mean & $95 \% \mathrm{Cl}$ & SD & Mean & $95 \% \mathrm{Cl}$ & SD \\
\hline \multicolumn{7}{|l|}{ Males $(n=123)$} \\
\hline Energy (kcal) & 2,112 & $1,996-2,229$ & 652 & 1,927 & $1,837-2,017$ & 504 \\
\hline Protein (g) & 87 & $82-92$ & 29 & 78 & $75-81$ & 18 \\
\hline Carbohydrate (g) & 284 & $266-302$ & 99 & 275 & $259-290$ & 84 \\
\hline Total fat (g) & 61 & $57-65$ & 22 & 51 & $52-57$ & 14 \\
\hline Saturated fat (g) & 17 & $16-18$ & 7 & 16 & $15-16$ & 4 \\
\hline Polyunsaturated fat (g) & 11 & $10-11$ & 4 & 10 & $10-11$ & 3 \\
\hline Cholesterol (mg) & 259 & $246-279$ & 112 & 265 & $256-274$ & 51 \\
\hline Fiber (g) & 11 & $10-12$ & 5 & 11 & $11-12$ & 4 \\
\hline Calcium (mg) & 365 & $332-398$ & 186 & 355 & $331-378$ & 133 \\
\hline Iron (mg) & 11 & $10-12$ & 4 & 11 & $10-11$ & 2 \\
\hline Vitamin A (retinol equivalent) & 692 & $528-857$ & 922 & 681 & $608-754$ & 410 \\
\hline \multicolumn{7}{|l|}{ Females $(n=140)$} \\
\hline Energy (kcal) & 1,464 & $1,377-1,551$ & 520 & 1,520 & $1,448-1,591$ & 428 \\
\hline Protein (g) & 61 & $57-65$ & 24 & 62 & $58-65$ & 20 \\
\hline Carbohydrate (g) & 199 & $188-210$ & 67 & 206 & $197-215$ & 55 \\
\hline Total fat (g) & 45 & $41-48$ & 21 & 46 & $43-48$ & 17 \\
\hline Saturated fat (g) & 12 & $11-13$ & 6 & 12 & $12-13$ & 4 \\
\hline Polyunsaturated fat (g) & 7 & $6-7$ & 3 & 7 & $6-7$ & 2 \\
\hline Cholesterol (mg) & 176 & 159-194 & 107 & 185 & 173-198 & 73 \\
\hline Fiber (g) & 9 & $8-9$ & 5 & 9 & $8-10$ & 4 \\
\hline Calcium (mg) & 345 & $312-378$ & 199 & 325 & $303-347$ & 131 \\
\hline Iron (mg) & 8 & $7-8$ & 4 & 8 & $8-9$ & 3 \\
\hline Vitamin A (retinol equivalent) & 639 & $476-801$ & 972 & 659 & $591-728$ & 408 \\
\hline
\end{tabular}

the high intra-individual variability of the intake of these items.

Among the adults, cholesterol and vitamin A presented the highest intra-individual variability (over $80 \%$ of the total intake variability). Additionally, men presented higher within variances than women, except for energy, which were about the same for men and women and for carbohydrates and fiber that were more variable among women. The variances ratio for protein and iron estimated for men were about double the values observed for women.

In this study, the number of required 24-hour recalls and food records replications among men can reach 67 days if a high degree of correlation $(\mathrm{r}=0.9)$ between observed and actual cholesterol intake is considered. Along the different degrees of expected correlation coefficient, the number of $24 \mathrm{hR}$ or food record replications required to estimate energy intake was identical for men and women. Conversely, when considering the admitted error in the estimation of actual energy intake, the number of replications was greater for women than for men.

Nelson et al. 21 observed that the variance ratios were higher for women than for men, except for vitamin $\mathrm{B}_{12}$. Oh \& Hong 22 observed that women over 60 also presented higher intra-individual variability than men of the same age: for the females, the within/between variances ratio ranged from 1.6 (carbohydrates) to 2.9 (fat), while among men, this ratio ranged from 1.4 (vitamin $\mathrm{B}_{2}$ ) to 4.5 (vitamin $\mathrm{B}_{1}$ ). On the other hand Tokudome et al. 23 indicated that to estimate usual energy and macronutrient intake of female Japanese dietitians between $10-35$ days of $24 \mathrm{hR}$ or food records replications would be needed, when considering a $10 \%$ error. These results were comparable to the number of $24 \mathrm{hR}$ and food records replications calculated in this study for women (20-36 days of replication) with the same degree of precision.

Comparing male adolescents and adults, it was observed that the intra-individual variabil- 
ity was higher among men than among boys, except for fiber, which presented a higher within/ between variance ratio (2.2 vs. 1.7). The within/ between variance ratio for cholesterol intake among men and boys was strikingly contrasting (15.6 vs. 2.9); this finding could be related to the dietary habits of adult males which are more prone to eat cholesterol rich food, like snacks that accompany alcoholic beverages. Conversely, energy and nutrient intake variability was comparable for female adults and adolescents, except for polyunsaturated fat which presented higher intra-individual variability among the girls (2.8 vs. 9.0). The differences in the methods applied for obtaining data on dietary intake in adults and adolescents (24hR and food records) and the quality of the dietary report may have influenced those results.

Gender and age are an important source of variability in dietary intake. Also it has been reported that there are differences in the intake of certain foods in diverse groups 20 , therefore the intake of nutrients is expected to vary according to the level of education, family size, smoking habits and physical activity ${ }^{11}$. However, estimating the within/between variances ratio taking into account too many factors may result in reduced between-subject variance and elevated variance ratio, which will require more replications of $24 \mathrm{hR}$ or food records to obtain accurate estimates of energy and nutrient intakes 7,24.

This analysis did not consider the effect of other confounders besides sex and age range; therefore the observed between-subject variance can be overestimated and the variances ratio at- tenuated, that could lead to sub-estimation on the number of $24 \mathrm{hR}$ and food records replications estimated. Nevertheless, our results were close to other similar studies, particularly those related to the within/between variances in adolescents and to the number of $24 \mathrm{hR}$ or diet records replications for women 4,23 .

In this study, data on food intake was obtained for non consecutive days and included one weekend day per individual. As a result, the day of the week effect was avoided, as were misleading correlations associated with consecutive days of dietary assessment ${ }^{3}$.

The number of replications of $24 \mathrm{hR}$ or food records to be adopted is dependent on the dietary factor under analysis, the study objectives, and the available resources. In large epidemiological studies, usually, too many $24 \mathrm{hR}$ or food record replications is costly and operationally complicated. Sometimes, it is recommended to carry out a separate study in a sub sample of the study population with a reasonable number of dietary assessment replications to allow the correction of food intake estimates.

In the present study, the variability in food intake was larger among female adolescents and male adults. As expected, the variability in macro and micronutrient intake was greater than the variance in the intake of energy, particularly for micronutrients that are concentrated on few food items like vitamin A. Due to within variance, more observations were required to obtain estimates of absolute usual intakes than to classify subjects according to levels of energy and nutrients intake.

\section{Resumo}

Na avaliação da dieta é preciso conhecer o mínimo de replicações de recordatórios de 24 horas e de registros alimentares necessários para estimar o consumo usual ou para classificar indivíduos em categorias de consumo. Foram analisados dados de dois diferentes estudos desenvolvidos na área metropolitana do Rio de Janeiro, Brasil, com 300 adultos e 169 adolescentes. Para estimar o número de replicações foram aplicados dois métodos: um baseado na razão das variâncias $e$ outro usando somente a variância intra-individual. $O$ achado mais importante foi a necessidade de 14 replicações para meninos e homens, 15 para meninas e 23 para mulheres quando se deseja uma precisão de $90 \%$ na estimativa do consumo de energia. São necessárias 4 replicações para meninos e 7 para homens, meninas e mulheres para categorizar o consumo de energia considerando coeficiente de correlação de 0,9. Devido à variância intra-individual do consumo alimentar é necessário maior número de replicações de inquéritos dietéticos para estimar o consumo usual do que para classificar os indivíduos segundo o consumo alimentar.

Consumo de Alimentos; Inquéritos sobre Dietas; Adulto; Adolescente 


\section{Contributors}

R. A. Pereira participated in the study conception and coordination, data analysis, manuscript writing and revising. M. C. Araujo and T. S. Lopes participated in data collection, data analysis, manuscript writing. E. M. Yokoo participated in the study conception, data analysis, manuscript writing and revision.

\section{Acknowledgments}

This study was supported by the National Research Council (CNPq). M. C Araujo and T. S. Lopes were supported by the Graduate Studies Coordinating Board (CAPES) during their Masters and Doctorate degree works. The authors wish to thank Dr. Rosely Sichieri for her support in the study design and development.

\section{References}

1. Beaton GH. Approaches to analysis of dietary data: relationship between planned analyses and choice of methodology. Am J Clin Nutr 1994; 59(1 Suppl):253S-61S.

2. Jahns L, Arab L, Carriquiry A, Popkin BM. The use of external within-person variance estimates to adjust nutrient intake distributions over time and across populations. Public Health Nutr 2005; 8: 69-76.

3. Willett WC. Nutritional epidemiology. Oxford: Oxford University Press; 1998.

4. Costa MMF, Takeyama L, Voci SM, Slater B, Silva MV. Within- and between-person variations as determinant factors to calculate the number of observations to estimate usual dietary intake of adolescents. Rev Bras Epidemiol 2008; 11:541-8.
5. Rutishauser IHE. Dietary intake measurements. Public Health Nutr 2005; 8:1100-7.

6. Paeratakul S, Popkin BM, Kohlmeier L, Hertz-Picciotto I, Guo X, Edwards LJ. Measurement error in dietary data: implications for the epidemiologic study of the diet-disease relationship. Eur J Clin Nutr 1998; 52:722-7.

7. Palaniappan U, Cue RI, Payette H, Gray-Donald K. Implications of day-to-day variability on measurements of usual food and nutrient intakes. J Nutr 2003; 133:232-5.

8. Huybrechts I, De Bacquer D, Cox B, Temme EH, Van Oyen H, De Backer G, et al. Variation in energy and nutrient intakes among pre-school children: implications for study design. Eur J Public Health 2008; 18:509-16. 
9. Gibson RS. The principles of nutritional assessment. Oxford: Oxford University Press; 2005.

10. Voci SM, Slater B, Silvia MV, Marchioni DML, Latorre MRDO. Estudo de calibração do Questionário de Freqüência Alimentar para Adolescentes - QFAA. Ciênc Saúde Coletiva; in press.

11. Black AE, Cole TJ, Wiles SJ, White F. Daily variation in food intake of infants from 2 to 18 months. Hum Nutr Appl Nutr 1983; 37:448-58.

12. Beaton GH, Milner J, Corey P, McGuire V, Cousins M, Stewart E, et al. Sources of variance in 24-hour dietary recall data: implications for nutrition study design and interpretation. Am J Clin Nutr 1979; 32:2546-59.

13. World Health Organization. Physical status: the use and interpretation of anthropometry. Geneva: World Health Organization; 1995. (WHO Technical Report Series, 854).

14. Cole TJ, Bellizzi MC, Flegal KM, Dietz WH. Establishing a standard definition for child overweight and obesity worldwide: international survey. BMJ 2000; 320:1240-3.

15. Fisberg RM, Villar BS. Manual de receitas e medidas caseiras para cálculo de inquéritos alimentares: manual elaborado para auxiliar o processamento de dados de inquéritos alimentares. São Paulo: Signus; 2002

16. Pinheiro ABV, Lacerda EMA, Benzecry EH, Gomes MCS, Costa VM. Tabela para avaliação de consumo alimentar em medidas caseiras. Rio de Janeiro: Editota Atheneu; 2008.

17. Nusser SM, Carriquiry AL, Dodd KW, Fuller WA. A semi-parametric transformation approach to estimating usual intake distributions. J Am Stat Assoc 1996; 91:1440-9.
18. Nusser SM, Fuller WA, Guenther PM. Estimating usual dietary intake distributions: adjusting for measurement error and no normality in 24-hour food intake data. In: Lyberg L, Biemer P, Collins M, Leeuw ED, Dippo C, Schwarz N, et al., editors. Survey measurement and process quality. New York: Wiley and Sons; 1997. p. 689-709.

19. Dodd KW, Guenther PM, Freedman LS, Subar AF, Kipnis V, Midthune D, et al. Statistical methods for estimating usual intake of nutrients and foods: a review of the theory. J Am Diet Assoc 2006; 106:1640-50.

20. Tooze JA, Midthune D, Dodd KW, Freedman LS, Krebs-Smith SM, Subar AF, et al. A new statistical method for estimating the usual intake of episodically consumed foods with application to their distribution. J Am Diet Assoc 2006; 106:1575-87.

21. Nelson M, Black AE, Morris JA, Cole TJ. Betweenand within-subject variation in nutrient intake from infancy to old age: estimating the number of days required to rank dietary intakes with desired precision. Am J Clin Nutr 1989; 50:155-67.

22. Oh SY, Hong MH. Within- and between-person variation of nutrient intakes of older people in Korea. Eur J Clin Nutr 1999; 53:625-9.

23. Tokudome Y, Imaeda N, Nagaya T, Ikeda M, Fujiwara N, Sato J, et al. Daily, weekly, seasonal, within- and between-individual variation in nutrient intake according to four season consecutive 7 day weighed diet records in Japanese female dietitians. J Epidemiol 2002; 12:85-92.

24. Sempos CT, Johnson NE, Smith EL, Gilligan C. Effects of intraindividual and interindividual variation in repeated dietary records. Am J Epidemiol 1985; 121:120-30.

Submitted on 15/Sep/2009

Final version resubmitted on 26/Jun/2010

Approved on 09/Jul/2010 